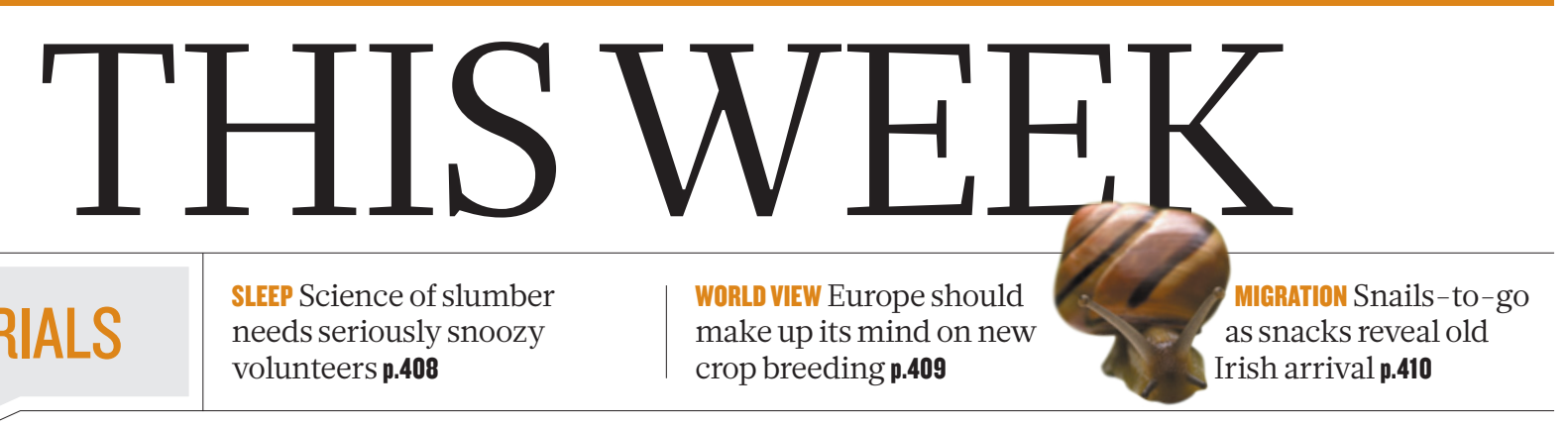

\title{
A culture of consent
}

\section{More than 50 years after the WI-38 cell line was derived from a fetus, science and society has still to get to grips with the ethical issues of using human tissue in research.}

$\mathrm{T}$ Tissue is removed from a woman in hospital. A scientist grows the tissue into a cell line. The cell line becomes one of the most important medical tools worldwide. Millions of lives are saved and millions of dollars made. The woman who made the breakthrough possible and her family are largely forgotten. Sound familiar?

That story describes the development of the famous HeLa cell line, grown from cancer tissue taken from a poor black woman without her consent, and brilliantly recorded by Rebecca Skloot in her best-seller The Immortal Life of Henrietta Lacks (Crown, 2010). But it also neatly summarizes a separate tale that has echoes of the HeLa case and raises many of the same ethical questions of consent and obligation. Until now, that story has failed to reach the broad audience it deserves.

The cell line in this case is called WI-38, in which the initials represent the Wistar Institute of Anatomy and Biology in Philadelphia, Pennsylvania, where the early work was done. WI-38 has arguably had an even bigger impact on science and medicine than the HeLa line. Whereas HeLa cells are cancerous, WI-38 cells are healthy and normal. They have been widely used for the production of virus vaccines given to many people worldwide - against rubella, for instance - and in research as a prototypical normal human cell.

As the News Feature on page 422 reports, the WI-38 cells came from a legally aborted fetus. More than half a century ago, a Swedish woman had her pregnancy terminated and the WI-38 cells were grown from tissue samples taken from the lungs of the fetus. That makes some people uncomfortable, but fetal tissue remains a useful and common tool in medicine today. In addition to its use in vaccine production, it has been used to make drugs against rheumatoid arthritis and cystic fibrosis. Therapies using cells derived from fetuses are being developed to treat haemophilia and to help patients on chemotherapy fight off infection.

\section{A QUESTION OF OWNERSHIP}

Last September, Leonard Hayflick, the scientist who derived the cell line, outlined the circumstances in a letter to Science (L. Hayflick Science 337, 1292; 2012). That letter was a direct response to the questions about the ownership of discarded tissue - and consent for using it — raised by Skloot's book.

Before her death, Henrietta Lacks was not asked for consent regarding the use of her cervical cancer cells. That was accepted practice in 1951, when the HeLa line was derived, as it was 11 years later when the Swedish woman had the legal abortion in 1962 that gave rise to WI-38.

Whether the woman was asked for or gave her consent to the use of the cells at the time of the abortion is not known, and whether she received any compensation seems highly unlikely. The gynaecologist who performed the abortion is dead, as is Sven Gard, the eminent Swedish virologist who arranged the transfer of the fetal lungs to Hayflick in the United States. Hayflick does not know. The woman involved has made it clear she does not want to talk about it and wants to be left alone.

The WI-38 story and Skloot's book both highlight how scientists,

companies and public health have all benefited from tissues with a troubled past - tissues that will stay in widespread use for decades because they are composed of self-replicating cells. Stanley Plotkin, inventor of the rubella vaccine, is quoted in the News Feature as saying that "retrospective ethics is easy but presumptuous". It is a point worth bearing in mind as scientists, physicians and the public try to navigate these issues.

The World Medical Association's Declaration of Helsinki, which laid out ethical recommendations for research involving human subjects,

"Whether human subjects are protected in research is a live question." \section{Still, whether human subjects are being} adequately protected in research is a live question. This was shown, for instance, by the controversy in March over whether the parents of premature infants were adequately informed when giving consent for a trial of oxygen therapy (see also A. J. Ammann Nature 498, 7; 2013).

Nor is it clear that scientists completely understand how technological progress is changing the debate about privacy. For instance, despite the publicity around Skloot's book, researchers this year published the HeLa genome (J. J. M. Landry et al. Genes Genomes Genet. http://doi.org/k22; 2013) without informing or asking the permission of Henrietta Lacks' surviving family. (The researchers later removed the sequence from databases after realizing that they had intruded on the family's privacy.)

In July 2011, the US Office for Human Research Protections provisionally proposed the first major revamp of the rules to govern human subjects in research in two decades. Among its suggestions is requiring written consent for the use of leftover tissues from surgeries and other procedures - even those that have been stripped of identifiers. The change is a necessary one, and crucial for public trust and accountability. Alas, nearly two years later, this change and others have not progressed even to the point of being issued as a firm proposal.

Another reason to press for a rule revision that goes the extra mile to involve tissue donors more is evident in Wisconsin. For the second time since 2011, a bill has been introduced to ban research with "any material derived from any cell or tissue of an unborn child".

Nature opposes the bill, introduced by André Jacque, a Republican member of the Wisconsin State Assembly. Yet it does raise an important issue. Written consents from donors of fetal tissue will not sway those who are opposed to abortion, but would certainly help the case for research. However strong the life-saving benefits seem to scientists and the medical profession, that case can always be - and should be - bolstered in the eyes of the public. On the use of tissue samples such as from the fetus from Sweden and from Henrietta Lacks, and the question of compensation, some would argue that mistakes may have been made. Some would disagree. All can agree there are lessons to learn. 